\title{
A Perspective on the Comorbidities of Chronic Migraine
}

\author{
Egilius LH Spierings* \\ Tufts University Schools of Medicine \& Dental Medicine, Boston, USA
}

Submission: September 21, 2017; Published: November 27, 2017

*Corresponding author: Egilius LH Spierings, Clinical Professor of Neurology \& Craniofacial Pain, Tufts University Schools of Medicine \& Dental Medicine, 72 Mount Auburn Street, Watertown, MA 02472, USA, Tel: 617-744-1310; Fax: 617-744-1285; Email: Spierings@MedVadis.com

\begin{abstract}
In contrast to episodic migraine, chronic migraine tends to be associated with a multitude of medical and psychiatric comorbidities. If they are taken into consideration, it is generally only to provide direction as to which category of medications to use preventively. When taken together etiologically, they are either ascribed to somatization disorder (DSM III/IV) or described as central sensitivity syndromes.

Common conditions that can accompany chronic migraine are, in random order: anxiety, depression, post-traumatic stress disorder (PTSD), insomnia, fatigue, myalgias of various sorts, including myofascial temporomandibular disorder (TMD), cervicalgia, and lumbago, fibromyalgia, chronic nausea, gastritis, acid reflux (GERD), constipation, irritable bowel syndrome (IBS), menstrual cycle disorders, and dysmenorrhea. It is proposed instead that the origin of the multitude of medical and psychiatric comorbidities of chronic migraine lies in a systemic endocrinemetabolic disorder. The muscular aspect of this disorder where it affects the craniocervical muscles, is postulated to constitute the target of Botox $®$ 's benefit in chronic migraine. This makes the painful muscles in the neck and shoulder region more than a comorbid condition, that is, a concomitant but unrelated pathological or disease process. The same may be true for some of the other comorbidities seen with chronic migraine, which, hence, should be addressed in the overall management of those patients.
\end{abstract}

Keywords: Episodic migraine; Chronic migraine; Comorbidities; Endocrinopathy; Multisystem disorder; Somatization disorder; Central sensitivity syndromes; Headache amplifier; Migraine pathogenesis

\section{Migraine Subdivisions}

The most common subdivisions of migraine are migraine with and without aura and episodic and chronic migraine [1]. These are subdivisions that consider different aspects of migraine, that is, whether the headaches are preceded or not by transient focal neurological symptoms, also known as aura symptoms, and whether the overall headache frequency is less than half the month or more, respectively. The subdivision into migraine with and without aura is interesting to neurologists but, otherwise, is without much consequence in terms of treatment or prognosis. The subdivision is historically based, going back to the subdivision of migraine into classic and common [2]. Classic migraine was always considered migraine while common migraine, formerly known as sick headache,was added in the first half of the last century. While migraine without aura is defined on the basis of the headaches, the definition of migraine with aura is based on the presence of transient focal neurological symptoms preceding or accompanying the headaches [1].
The subdivision of migraine into episodic and chronic is of a much more recent date. Frequent headache, the very characteristic of chronic migraine, was traditionally regarded as an exclusive feature of chronic tension headache, renamed chronic tension-type headache by the International Headache Society (IHS)[1]. It was considered a depression equivalent, prompting the introduction of amitriptyline in its preventive treatment [3], and was very much the work terrain of psychologists. However, it was realized that many patients with this condition, in addition to their frequent headaches, have headaches indistinguishable from migraine. Now we know that this is the case in about half of the patients with frequent headaches (vide infra), which often occur on a daily or almost daily basis.

The prevalence of both chronic tension-type headache and chronic migraine in the general population has been estimated at $2-3 \%[4]$. This is about one-fifth of the population prevalence of episodic migraine, which is estimated at $10-15 \%$ [5]. In practice, 
however, patients with chronic migraine are overrepresented among the migraine patients, easily accounting for at least half of cases [4]. This makes chronic migraine an important condition in medical practice. The subdivision of migraine into episodic and chronic, unlike that into with and without aura, is consequential probably both in terms of treatment and prognosis.

\section{Chronic Migraine}

The recognition of chronic migraine as a migraine rather than tension (-type)-headache condition certainly does justice to the patients, which is important. It is interesting that this was also the consideration that drove the inclusion of sick headache, via common migraine and ultimately as migraine without aura, into the migraine classification [2]. With the recognition comes the potential use of the abortive and preventive migraine medications in the treatment, an important step forward for the patients. The response to treatment is, however, not different for migraine with or without aura, either abortively or preventively, although, admittedly, this has not been thoroughly studied.

Treatment responsiveness of episodic versus chronic migraine has also not been studied well but there is evidence from clinical trials that topiramate is effective as preventive treatment in both [6-9], while botulinum toxin is only effective as preventive treatment in chronic migraine [10,11]. In regard to the latter, the FDA labeling for Botox ${ }^{\circledR}$ (Allergan, Parsippany, New Jersey), the best known and most widely used botulinumtoxin formulation, states: "BOTOX $®$ (onabotulinumtoxinA) is a prescription medicine that is injected to prevent headaches in adults with chronic migraine who have 15 or more days each month with headache lasting 4 or more hours each day in people 18 years or older. It is not known whether BOTOX® is safe or effective to prevent headaches in patients with migraine who have 14 or fewer headache days each month (episodic migraine)". Hence, distinguishing chronic migraine from episodic migraine seems relevant for treatment, at least from the perspective of treating the condition with botulinum toxin.

In terms of subdividing migraine into episodic and chronic, the International Headache Society takes a very pragmatic but at the same time highly simplistic approach [1]. It divides the total number of headache days per month into less than half the month or more and, in this way, divides migraine into episodic and chronic. The biological basis of this rather arbitrary subdivision seems to be substantiated by the differential response to preventive treatment with botulinum toxin. If this subdivision does, indeed, have a biological basis, the question arises as to what the substrate is of botulinum toxin's benefit in chronic migraine that is not operational in episodic migraine.

It is understood that the difference in headache frequency bestows much greater suffering on the patient with chronic migraine than on the one with episodic migraine. However, the greater suffering also originates from the multitude of medical and psychiatric comorbidities the patient with chronic migraine is often afflicted with, in contrast to the patient with episodic migraine. This may present a much more important reason to distinguish chronic migraine from episodic migraine because it impacts both treatment and prognosis.

\section{Case Histories}

The following two cases are typical presentations, illustrative of the patient with chronic migraine. Two relatively young patients are featured here because of the author's initial believe that patients with chronic migraine acquire their comorbidities over the course of a life-long migraine suffering, which is clearly not the case. The comorbidities are more likely to be an integral part of the chronic migraine condition, which makes them more than comorbidities, that is concomitant but unrelated (italicized by author) pathological or disease processes (The American Heritage ${ }^{\circledR}$ Medical Dictionary).

\section{Case I}

Patient was an 18-year-old woman with migraine since age 11 years (menarche at age 12). The headaches occurred daily and usually came on during the day but not at any particular time. They were moderately severe in intensity (7-8/10) but were severe (9-10/10) once or twice per week for $1-2$ days. The headaches were located in the forehead, eyes, temples, and back of the head. They were throbbing in nature and made worse by physical activity. The headaches were not preceded by aura. They were associated with photophobia and phonophobia and when severe, also with nausea. Apart from the headaches, she had insomnia and got, on average, only 5 hours of sleep per night. As a result, she felt tired during the day and rated her energy level as $2 / 10$. She had anxiety, depression, and attention deficit disorder (ADD). She had acid reflux (GERD) and diarrheapredominant irritable bowel syndrome (IBS-D). Her neck and shoulder muscles were tight and sore (cervical myalgia).

\section{Case II}

Patient was a 20-year-old woman with migraine since age 13 years (menarche at age 12). The headaches occurred almost daily and were often present at moderate intensity (5/10) on awakening in the morning. Approximately half of the week, they increased in intensity to become severe $(8 / 10)$ by early afternoon, otherwise they remained moderate. The headaches were generalized in location but, when severe, concentrated in the left forehead and eye. They were throbbing in nature and made worse by physical activity. The headaches were not preceded by aura. They were associated with photophobia and phonophobia and when severe, also with nausea and, on average, twice per month with vomiting. Apart from the headaches, she had insomnia and got, on average, 6-7 hours of interrupted sleep per night. As a result, she felt tired during the day and rated her energy level as 6/10. She had depression as well as irritable bowel syndrome, alternating with constipation and diarrhea (IBS-M). Her periods occurred twice per month (polymenorrhea), lasted for 7 days and were heavy (hypermenorrhea) and very painful 
(dysmenorrhea). Her neck and shoulder muscles were tight and sore (cervical myalgia) and she had had low-back pain since childhood (lumbago).

\section{Endocrinopathy}

Migraine is very much a female condition with a male-tofemale ratio in terms of population prevalence of 1 to 2-3 [12]. Estrogen hormones undoubtedly play an important role here as suggested 1) by the common onset of migraine in women at menarche, with the use of an estrogen-containing contraceptive, or during and particularly after pregnancy [13] and 2) by the occurrence or worsening of migraine in women particularly perimenstrually [14]. Determining menstrual-cycle and menstruation disorders in women with episodic versus chronic migraine, Spierings \& Padamsee [14] found a statistically significantly higher occurrence of menstrual-cycle disorders in general (oligomenorrhea, polymenorrhea, and irregular cycle) in women with chronic migraine (41.2\% versus $22.2 \%$; $\mathrm{p}=0.05$ ) and also dysmenorrhea (51.0\% versus $28.9 \%$; $\mathrm{p}=0.04$ ). A cause of severe dysmenorrhea is endometriosis a condition in which endometrium is present in the pelvis and/or abdomen outside the uterus. Tietjen et al. [15] found this condition to be statistically significantly more common in women with chronic migraine than in those with episodic migraine $(64 \%$ versus 36\%; $\mathrm{p}=0.002$ ).

Expanding on the theme of comorbidities in episodic versus chronic migraine, Bigal et al. [16] found statistically significantly higher odd ratios for asthma $(2.4)(\mathrm{p}=0.03)$, allergies (3.5) $(\mathrm{p}=0.0001)$, hypertension $(6.9)(\mathrm{p}<0.0001)$, and hypothyroidism $(8.4)(p=0.0004)$, in chronic migraine. Allergies and hypothyroidism as increased comorbidities in chronic migraine were not confirmed by Ferrari et al. [17] and neither was hypothyroidism by Spierings \& Padamsee [14]. Ferrari et al. [17] confirmed hypertension and added insomnia and constipation as well as psychiatric, gastrointestinal, musculoskeletal, ocular, genitourinary, hematologic, cerebrovascular, and cardiac disorders. They did not describe any of these disorders in detail but common conditions comorbid with chronic migraine, apart from insomnia, constipation, and dysmenorrhea are, in random order: anxiety, depression, fatigue, myalgias of various sorts, including myofascial temporomandibular disorder (TMD), cervicalgia, and lumbago, fibromyalgia, acid reflux (GERD), chronic nausea, irritable bowel syndrome (IBS), and menstrual cycle disorders.

Regarding the myalgias mentioned above, neck pain or cervicalgia was specifically studied by Florencio et al. [18], who compared 65 patients with chronic migraine with 104 patients with episodic migraine. They found $63 \%$ of the chronic migraine patients to have neck pain as opposed to $36 \%$ of those with episodic migraine, a statistically significant difference although the p-value was not mentioned. They also reported an increased prevalence of difficulty sleeping in the chronic migraine patients versus those with episodic migraine (69\% versus $44 \%$; $\mathrm{p}<0.001$ ), confirming Ferrari et al. [17] observation. In terms of pain in the neck and shoulder muscles specifically, Landgraf et al. [19] compared two groups of adolescents with episodic migraine, that is, with headaches less than once per week $(n=99)$ and headaches weekly ( $n=195)$, with those with chronic migraine $(n=66)$. They also included a control group without headache in their study $(n=241)$ and found the prevalence of neck/shoulder pain to statistically significantly increase with headache frequency (test for trends: $\mathrm{p}<0.0001$ )(Figure 1).

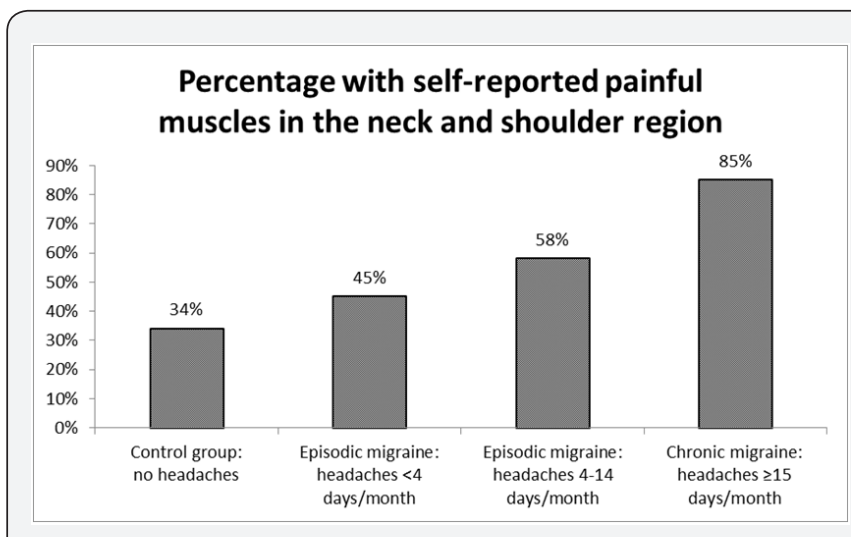

Figure 1: Percentage of adolescents with self-reported pain in the neck and shoulder muscles, comparing those with low- and high-frequency episodic migraine with those without headaches (control group) and those with chronic migraine (test for trends: $p<0.0001)$. Data obtained from Landgraf et al. [19].

A comprehensive review of the psychiatric comorbidities of chronic versus episodic migraine was provided by Buse et al. [20]. They looked at depression, anxiety disorders, post traumatic stress disorder (PTSD), and substance abuse. They found moderate-to-severe depression and a medical diagnosis of depression almost twice as common in chronic than in episodic migraine. The same is true for moderate-to-severe anxiety and a medical diagnosis of anxiety is almost $1 \frac{1}{2}$ times as common in chronic migraine than in episodic migraine. The situation is less clear for PTSD and there is no evidence to suggest that substance abuse is more often associated with chronic migraine than it is with episodic migraine.

\section{Multisystem Disorder}

Certainly, the presentation with a multisystem disorder is not unique to the patient with chronic migraine. It seems to be a feature of the chronic patient in general, who suffers from persistent complaints, generally not one but multiple, originating from different organ systems, medically and psychiatrically. The following case, again for illustrative purpose only, is just one example of this multisystem disorder presentation but numerous similar cases could be described here.

\section{Case III}

The patient was a 34-year-old woman who developed pressure in her temples, tight jaws, and pain in her shoulders following pregnancy. Apart from these complaints, she had long (8-9 days) and heavy periods (hypermenorrhea), which were very painful (dysmenorrhea) from menarche until the 
pregnancy. The periods occurred regularly and on a monthly basis but, nevertheless, she had infertility. Her epigastric area was tender and suggestive of gastritis and she had constipationpredominant irritable bowel syndrome (IBS-C). She also had anxiety. She slept well and got 7-8 hours of sleep per night but, nevertheless, felt tired during the day as well as weak in general.

\section{Somatization disorder}

The patient with multisystem complaints is a medical enigma and hence, we are thrown back again into the realm of psychology. In psychology, there is a nosological entity known as somatization disorder, which entered the Diagnostic and Statistical Manual of Mental Disorders in its 3rd edition in 1980 [21] and exited in its 5th edition in 2013 [22]. Briefly, it is defined as a polysymptomatic disorder that begins before the age of 30 years, extends over a period of years, and is characterized by a combination of pain, gastrointestinal, sexual, and pseudoneurological symptoms. Under its diagnostic criteria, it is added that the numerous physical complaints result in treatment being sought or significant impairment in social, occupational, or other important areas of functioning.

In the 5th edition of the Diagnostic and Statistical Manual of Mental Disorders, a totally different approach is taken [22]. Now, more than 3 decades later, it is no longer considered appropriate to give an individual a diagnosis of a mental disorder, solely because he or she has complaints for which a medical cause cannot be establised. It is stated that the previous criteria, that is, those for somatization disorder, overemphasized the centrality of medically unexplained symptoms and that a diagnosis of somatic symptom disorder, the term that replaced somatization disorder, can also accompany diagnosed medical disorders. Hence, somatic symptom disorder is a secondary diagnosis that can be made, if there are:

A. One or more somatic symptoms that are distressing or result in significant disruption of daily life

B. Excessive thoughts, feelings, or behaviors related to the somatic symptoms or associated health concerns and

C. Although any one somatic symptom may not be continuously present, the state of being symptomatic is persistent (typically more than 6 months).

\section{Central sensitization syndromes}

Apart from being ascribed to a somatization disorder, the comorbidities as seen, amongst others, with chronic migraine have also been described as central sensitization syndromes [23]. These syndromes have been attributed to "central sensitization" and, hence, in this context are given a neurological rather than psychiatric explanation. The idea behind central sensitization is that there is activation of nociceptive C- and A $\delta$-fibers in peripheral tissues, causing a barrage of impulses entering the central nervous system. In the central nervous system, they activate second-order neurons to the extent that hyperexcitability develops involving nociceptive as well as non-nociceptive neurons. As second-order neurons are also subject to descending facilitatory and inhibitory influences, these modulatory systems may also partake in the pathogenesis of the syndromes. The theory mostly derives its support from neurophysiological studies of a sensory nature, suggesting hypersensitivity to electrical, thermal, or mechanical stimuli.

\section{Systemic endocrine-metabolic disorder}

With psychiatry having abandoned somatization disorder and medicine looking to explain the comorbidities neurologically, the author, a neurologist, would like to move the pendulum back to medicine and suggest a systemic endocrine-metabolic disorder. The metabolic aspect of this disorder centers around energy metabolism, accounting for the fatigue, that is, lack of metabolic energy, as an almost ubiquitously present symptom among the comorbidities. Metabolic energy is essential for the functioning of all organs in the body and a disturbance in this system could easily explain a multisystem disorder. However, the picture does not tend to be complete without implicating the endocrine system, particularly the female reproductive system. Of course, part of the endocrine system, that is, the thyroid system, also plays an important role in energy metabolism and a two-way interaction may well exist.

\section{Epilogue}

Migraine is considered to belong to the central sensitivity syndromes [23] but it is the author's opinion that it is not and that, instead, it is more like a headache amplifier, genetically determined and familial in nature. A patient affected by the multisystem comorbidity disorder becomes a chronic migraine sufferer if he or she also harbors the constellation of genes that transfers the vulnerability for migraine. Under those circumstances, the pressure in the head as in the patient in case III turns into headaches, often severe as in the patients in cases I and II.

Finally, regarding the differential benefit of botulinum toxin in chronic versus episodic migraine, the lack of benefit in the latter suggests that the medication does not have its mode of action specifically related to migraine headache mechanisms. A long-acting muscle relaxant, it is suggested that it acts on the craniocervical hypertonia where the injections are placed, which in patients such as described in case III causes persistent pressure in the temples. Along with the genetically determined and inherited headache amplifier, in patients such as described in cases I and II, it causes persistent migraine headaches or, in other words, chronic migraine.

\section{Conflict of interest statement}

The manuscript was written without external funding.

\section{Referances}

1. Headache Classification Committee of the International Headache Society (2013) The international classification of headache disorders. ( $3^{\text {rd }}$ edn), (beta version). Cephalalgia 33(9): 629-808.

2. (1962) Committee on Classification of Headache of the National Institute of Neurological Diseases and Blindness. Classification of headache. JAMA 179: 717-718. 


\section{Open Access Journal of Neurology \& Neurosurgery}

3. Diamond S, Baltes BJ (1971) Chronic tension headache treated with amitriptyline-a double-blind study. Headache 11(3): 110-116.

4. Piekos K, Spierings ELH (2009) Management of daily headache unresponsive to preventive treatment: daily triptans versus daily opioids. Rev Neurol Dis 6(4): E121-E130.

5. Goldstein M, Chen TC (1982) The epidemiology of disabling headache. Adv Neurol 33: 377-390.

6. Silberstein SD, Neto W, Schmitt J, Jacobs D, MIGR-001 Study Group (2004) Topiramate in migraine prevention. Results of a large controlled study. Arch Neurol 61(4): 490-495.

7. Brandes JL, Saper JR, Diamond M, Couch JR, Lewis DW, et al. (2004) Topiramate for migraine prevention. A randomized controlled trial. JAMA 291(8): 965-973.

8. Diener HC, Bussone G, Van Oene JC, Lahaye M, Schwalen S, et al. (2007) Topiramate reduces headache days in chronic migraine: a randomized, double-blind, placebo-controlled study. Cephalalgia 27(7): 814-823.

9. Silberstein SD, Lipton RB, Dodick DW, Freitag FG, Ramadan N, et al (2007) Efficacy and safety of topiramate for the treatment of chronic migraine: a randomized, double-blind, placebo-controlled study. Headache 47(2): 170-180.

10. Aurora SK, Dodick DW, Turkel CC, DeGryse RE, Silberstein SD, et al (2010) Onabotulinumtoxin A for treatment of chronic migraine results from the double-blind, randomized, placebo-controlled phase of the PREEMPT 1 trial. Cephalalgia 30(7): 793-803.

11. Diener HC, Dodick DW, Aurora SK, Turkel CC, DeGryse RE, et al. (2010) Onabotulinumtoxin A for treatment of chronic migraine: results from the double-blind, randomized, placebo-controlled phase of the PREEMPT 2 trial. Cephalalgia 30(7): 804-814.

12. Rasmussen BK, Jensen R, Schroll M, Olesen J (1991) Epidemiology of headache in a general population - a prevalence study. J Clin Epidemiol 44(11): 1147-1157.

13. Karpouzis KM, Spierings ELH (1999) Circumstances of onset of chronic headache in patients attending a specialty practice. Headache 39(5): 317-320.

This work is licensed under Creative Commons Attribution 4.0 Licens

DOI: 10.19080/OAJNN.2017.06.555688
14. Spierings ELH, Padamsee A (2015) Menstrual-cycle and menstruation disorders in episodic versus chronic migraine: an exploratory study. Pain Med 16(7): 1426-1432.

15. Tietjen GE, Bushnell CD, Herial NA, Utley C, White L, et al. (2007) Endometriosis is associated with prevalence of comorbid conditions in migraine. Headache 47(7): 1069-1078.

16. Bigal ME, Sheftell FD, Rapoport AM, Tepper SJ, Lipton RB (2002) Chronic daily headache: identification of factors associated with induction and transformation. Headache 42(7): 575-581.

17. Ferrari A, Leone S, Vergoni AV, Bertolini A, Sances G, et al. (2007) Similarities and differences between chronic migraine and episodic migraine. Headache 47(1): 65-72.

18. Florencio LL, Chaves TC, Carvalho GF, Gonçalves MC, Casimiro EC, et al. (2014) Neck pain disability is related to the frequency of migraine attacks: a cross-sectional study. Headache 54(7): 1203-1210.

19. Landgraf MN, Von Kries R, Heinen F, Langhagen T, Straube A, et al. (2016) Self-reported neck and shoulder pain in adolescents is associated with episodic and chronic migraine. Cephalalgia 36(8): 807-811.

20. Buse DC, Silberstein SD, Manack AN, Papapetropoulos S, Lipton RB (2013) Psychiatric comorbidities of episodic and chronic migraine. J Neurol 260(8): 1960-1969.

21. American Psychiatric Association (1980) Diagnostic and Statistical Manual of Mental Disorders. ( $3^{\text {rd }}$ edn), American Psychiatric Association, Washington, DC, USA.

22. American Psychiatric Association (2013) Diagnostic and Statistical Manual of Mental Disorders. (5 ${ }^{\text {th }}$ edn), American Psychiatric Association, Washington, DC, USA.

23. Yunus MB (2008) Central sensitivity syndromes: a new paradigm and group nosology for fibromyalgia and overlapping conditions, and the related issue of disease versus illness. Semin Arthritis Rheum 37(6): 339-352.

\section{Your next submission with Juniper Publishers} will reach you the below assets

- Quality Editorial service

- Swift Peer Review

- Reprints availability

- E-prints Service

- Manuscript Podcast for convenient understanding

- Global attainment for your research

- Manuscript accessibility in different formats

( Pdf, E-pub, Full Text, Audio)

- Unceasing customer service

Track the below URL for one-step submission

https://juniperpublishers.com/online-submission.php 